\title{
Carbohydrates
}

\section{Carbohydrate digestion and absorption}

\section{R. HOLMES}

From the Royal Infirmary, Manchester
In the western hemisphere an adult ingests more than $300 \mathrm{~g}$ of carbohydrate daily and this provides at least $50 \%$ of the total calorie intake (Table I). Most is in the form of starch and sucrose with a small contribution from lactose. Starch, the major food polysaccharide, consists of $85 \%$ amylopectin and $15 \%$ amylose. Amylose is composed of straight chains of glucose molecules linked through $1: 4-\alpha$ bonds (Fig. 1) whereas amylopectin, in addition to chains of $1: 4-\alpha$ linked glucose molecules, also has $1: 6-\alpha$ links between glucose molecules in adjacent chains forming bridges.

\begin{tabular}{lcl}
\hline & Intake $(g)$ & Percentage of Total \\
\hline $\begin{array}{l}\text { Polysaccharides } \\
\text { Starch }\end{array}$ & 200 & 64 \\
$\begin{array}{l}\text { Glycogen } \\
\text { Disaccharides }\end{array}$ & 1 & $0 \cdot 5$ \\
$\begin{array}{l}\text { Sucrose } \\
\text { Lactose }\end{array}$ & 80 & 26 \\
$\begin{array}{l}\text { Monosaccharide } \\
\text { Fructose }\end{array}$ & 20 & $6 \cdot 5$ \\
\hline
\end{tabular}

Table I Average daily carbohydrate intake for an adult human subject

\section{Luminal Digestion}

Starch, sucrose, and lactose are not normally absorbed by the small intestine, and digestion by hydrolysis to the constituent monosaccharides is an essential step in their utilization. Although the $\alpha$ amylases of saliva as well as of pancreatic juice are capable of hydrolysing amylose and amylopectin, it is probable that the major part of this stage of digestion is carried out in the lumen of the small intestine by pancreatic $\alpha$-amylase (Dahlqvist and Borgstrom, 1961; Fogel and Gray, 1970). As shown in Fig. 1, only the $1: 4-\alpha$ link is hydrolysed by pancreatic $\alpha$-amylase, the $1: 6-\alpha$ bridge remaining intact. Thus, the products of polysaccharide digestion in the intestinal lumen are maltose, maltotriose, and $c$ $\alpha$-limit dextrins (Fig. 2), and under physiological ú conditions little or no glucose is formed (Roberts and Whelan, 1960). Also present in the small intestine at this stage are unchanged sucrose and lactose derived from food (Fig. 2).

\section{Membrane Digestion}

The end results of the action of pancreatic $\alpha$-amylase viz, maltose, maltotriose, and $\alpha$-limit dextrins together with sucrose and lactose, require furthes

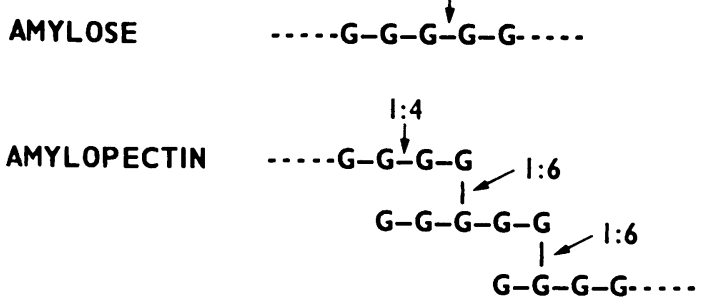

Fig. 1 Digestion of polysaccharide; pancreatic $\alpha$-amylase acts on the 1:4- $\alpha$ link only $(G=$ glucose $)$.

\begin{tabular}{ccl} 
RESULT & G.G & MALTOSE \\
& G.G.G & MALTOTRIOSE \\
& G.G.G & \\
& \multicolumn{1}{c}{ G.G.G.G } & \\
& & \\
ALSO & G.GIMIT DEXTRIN & \\
& G.F & LACTOSE \\
& & SUCROSE
\end{tabular}

Fig. 2 Results of digestion by pancreatic $\alpha$-amylase (Gal $=$ galactose, $F=$ fructose $)$. 
hydrolysis to their constituent monosaccharides before absorption. As early as 1880 Brown and Heron showed that enzymes hydrolysing disaccharides were present mainly in the intestinal mucosa rather than in the intestinal juice, and this finding has been repeatedly confirmed (Plimmer, 1907; Cajori, 1933; Borgström, Dahlqvist, Lundh, and Sjovall, 1957). Nevertheless, for many years it was generally considered that the terminal phase of carbohydrate digestion took place by the action of enzymes secreted into the lumen in the intestinal juice or succus entericus. Over the past 20 years attention has been focused on the intestinal epithelial cell and especially on the brush (microvillous) border at its luminal pole. The microvilli were shown histochemically to be the predominant site of certain hydrolytic enzymes (Johnson and Kugler, 1953; Nachlas, Monis, Rosenblatt, and Seligman, 1960), and in 1961 Miller and Crane (1961b) isolated intact brush borders from the small intestine of hamsters and showed that they possessed most of the disaccharidase activity of the mucosa. Over the past 10 years an impressive list of enzymatic and other functions has been found in brush borders from many species including man (Holmes, 1971), and it is now clear that terminal digestion of carbohydrates takes place at or on the surface of the intestinal epithelium and not in the lumen. Support for the concept of surface or 'membrane' digestion was provided by the localization of the disaccharidases to the terminal membrane of the brush border (Eichholz and Crane, 1965) and the demonstration of enzyme-rich knobs on the surface of the microvillous membrane (Oda and Seki, 1965; Johnson, 1967).

The brush border contains several disaccharidases which hydrolyse the end products of pancreatic $\alpha$-amylase digestion, and these are shown diagrammatically in Figure 3 . Thus, maltase acts on maltose and maltotriose liberating glucose, sucrase on sucrose releasing glucose and fructose, and lactase hydrolyses lactose to glucose and galactose. The enzyme splitting the $1: 6-\alpha$ link in the $\alpha$-limit dextrins is generally called 'isomaltase' but a better name

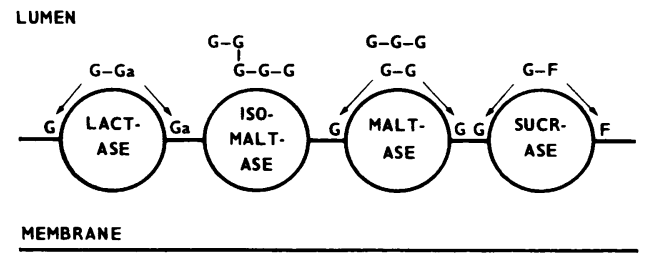

Fig. 3 Diagram illustrating membrane digestion by the disaccharidases of the brush border. would be ' $\alpha$-dextrinase' since the disaccharide isomaltose with the $1: 6-\alpha$ link is not present physiologically in the gut lumen. The oligosaccharides released by the action of isomaltase on $\alpha$-limit dextrins are finally split to glucose by the further action of pancreatic $\alpha$-amylase and the brush border enzymes (Alpers and Solin, 1970).

\section{The Absorption of Monosaccharides}

The digestion of carbohydrates has two phases, a luminal phase involving pancreatic $\alpha$-amylase and a membrane phase involving intestinal disaccharidases. As a result the starch, sucrose, and lactose ingested daily are broken down to monosaccharides, of which $80 \%$ is glucose, $15 \%$ fructose, and $5 \%$ galactose. The transport mechanisms involved in the absorption of these monosaccharides from the intestinal lumen are located in the brush border of the epithelial cell (Miller and Crane, 1961a; Newey, Sanford, and Smyth, 1963) at a site internal to the disaccharidase activity. Glucose and galactose are both absorbed by the same active transport process, which appears to be dependent on the presence of $\mathrm{Na}^{+}$ions (Crane, 1968). Fructose is absorbed less rapidly by a separate transport system (Holdsworth and Dawson, 1964) which is probably also an active process (Gracey, Burke, and Oshin, 1970). Figure 4 illustrates a way in which transport of water-soluble monosaccharides across the lipoprotein microvillous membrane could occur (Crane, 1965). The substrate and $\mathrm{Na}^{+}$are reversibly attached to a 'carrier' which effects translocation through the membrane. The monosaccharide can be transported against its

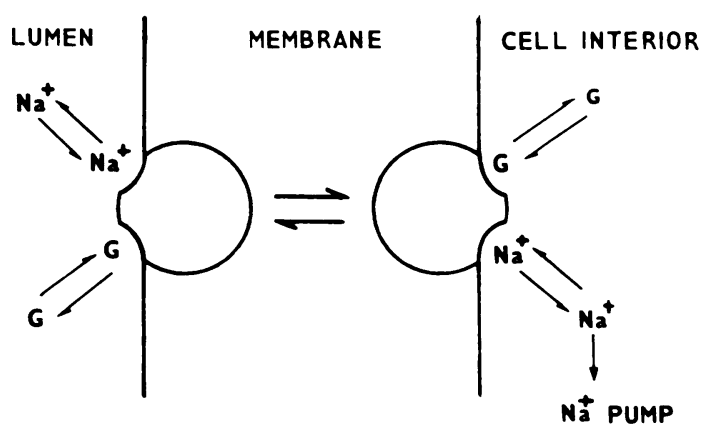

Fig. 4 Diagrammatic representation of $\mathrm{Na}^{+}$dependent glucose transport by means of a membrane carrier. Glucose is shown passing from low concentration in the lumen to high concentration in the cell. $\mathrm{Na}+$ is shown passing from high concentration in the lumen to low concentration in the cell (after Crane, 1965). 
concentration gradient, the energy for the transport process being provided at least in part by a concentration gradient of $\mathrm{Na}^{+}$across the membrane which is maintained by the $\mathrm{Na}^{+}$pump effectively removing $\mathrm{Na}^{+}$from the epithelial cell. Morphological identification of a 'mobile' carrier in the brush border membrane has not yet been made, though the isolated sucrase-isomaltase enzyme complex appears to possess carrier-like functions as well as hydrolytic properties (Semenza, 1970).

It is likely that the enzymes and carriers of the brush border membrane are spatially orientated in such a way as to cause the digestion and absorption of sugars to occur in a sequential manner. This integration of digestion and absorption is illustrated in Fig. 5, and here the hydrolysis of maltose by maltase is shown to release glucose which comes into such a functionally intimate relationship with the carrier that immediate transport ensues. The close association of the membrane components subserving enzymatic and carrier functions confers a 'kinetic advantage' for the absorption of disaccharides as compared with monosaccharides (Crane, 1967), and this is supported by the observation that glucose is better absorbed when given as sucrose than when given as free glucose (Fridhandler and Quastel, 1955; Miller and Crane, 1961a).

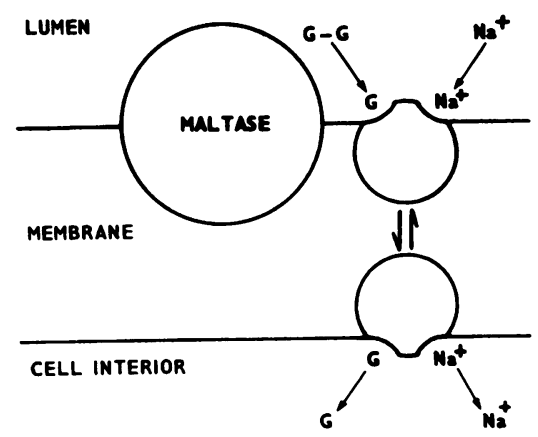

Fig. 5 Diagram illustrating the integration of digestion and absorption at the brush border membrane.

\section{The Absorption of Glucose in Man}

Virtually all the glucose in a mixed meal is absorbed in the upper jejunum (Borgstrom et al, 1957), transport across the brush border membrane being effected by a carrier mechanism (Schedl and Clifton, 1963; Holdsworth and Dawson, 1964). $\mathrm{Na}^{+}-$ dependent glucose absorption found in studies in vitro on the small intestine of animals (vide supra) has not been observed in man. Thus, in human perfusion experiments, Olsen and Ingelfinger (1968) found that the absorption of glucose from high luminal concentrations was independent of the $\mathrm{Na}^{+}$ concentration, and that $\mathrm{Na}^{+}$dependence only occurred at low intraluminal concentrations of glucose. The difference shown by animals and man concerning the relationship between glucose absorption and $\mathrm{Na}^{+}$concentration may reflect differences in the technical methods used, or even an actual species difference in the mechanism of absorption. However, it is possible that $\mathrm{Na}^{+}$-dependent glucose absorption obtains in man due to the presence of an 'unstirred' layer rich in $\mathrm{Na}^{+}$and forming a 'microclimate' immediately adjacent to the microvillous membrane on its luminal surface but which is not yet amenable to analysis by the perfusion techniques available in vivo.

\section{The Effects of Non-absorbed Disaccharides}

Normal human intestine absorbs little if any disaccharide as such, and if for any reason disaccharide hydrolysis does not occur, clinical symptoms may be provoked. The common symptoms are abdominal cramps, bloating, and diarrhoea, and these have been attributed to two main causes: (1) the osmotico effect of unabsorbed disaccharide, and (2) the metabolic change of unabsorbed disaccharide bye colonic bacteria. Thus, the disaccharide acts osmotically and causes a shift of fluid and salts into the intestinal lumen, the increased fluid passing to the colon (Fischer and Sutton, 1949). Here bacteria metabolize the disaccharide to organic acids which may increase the diarrhoea osmotically or by acting as irritants to the colonic mucosa. Recent observations (Christopher and Bayless, 1968) suggest that the osmotic effects of the unabsorbed substances in the small intestine and the colon play the major role in the causation of the diarrhoea.

\section{References}

Alpers, D. H., and Solin, M. (1970). The characterization of rat intestinal amylase. Gastroenterology, 58, 833-842.

Borgstrom, B., Dahlqvist, A., Lundh, G., and Sjovall, J. (1957). Studies of intestinal digestion and absorption in the human. J. clin. Invest., 36, 1521-1536.

Brown, H. T., and Heron, J. (1880). Uber die hydrolytischen Wirkungen des Pancreas und des Dunndarmes. Ann. Chem. Pharmacol., 204, 228-251.

Cajori, F. A. (1933). The enzyme activity of dog's intestinal juice and its relation to intestinal digestion. Amer. J. Physiol., 104, 659-668.

Christopher, N. L., and Bayless, T. M. (1968). Diarrhoea mechanism in lactase deficiency. (Abstr.) Clin. Res., 16, 261.

Crane, R. K. (1965). Na+-dependent transport in the intestine and other animal tissues. Fed. Proc., 24, 1000-1006.

Crane, R. K. (1967). Structural and functional organisation of an epithelial cell brush border. In Intracellular Transport, pp. 71103. Symposia of the International Society for Cell Biology, Vol. V. Academic Press, New York. 
Crane, R. K. (1968). Absorption of sugars. In Handbook of Physiology, Sect. 6: Alimentary Canal, Vol. III, Intestinal Absorption, pp. 1323-1351. American Physiological Society, Washington.

Dahlqvist, A., and Borgstrom, B. (1961). Digestion and absorption of disaccharides in man. Biochem. J., 81, 411-418.

Eichholz, A., and Crane, R. K. (1965). Studies on the organisation of the brush border in intestinal epithelial cells. I. Tris-disruption of isolated hamster brush borders and density gradient separation of fractions. J. Cell. Biol., 26, 687-691.

Fischer, J. E., and Sutton, T. S. (1949). Effects of lactose on gastrointestinal motility: a review. J. Dairy. Sci., 32, 139-162.

Fogel, M. R. and Gray, G. M. (1970). In Gray, G. M. Carbohydrate digestion and absorption. Gastroenterology, 58, 96-107.

Fridhandler, L. and Quastel, J. H. (1955). Absorption of sugars from isolated surviving intestine. Arch. Biochem., 56, 412-418.

Gracey, M., Burke, V., and Oshin, A. (1970). Intestinal transport of fructose. Lancet, 2, 827-828.

Holdsworth, C. D., and Dawson, A. M. (1964). The absorption of monosaccharides in man. Clin. Sci., 27, 371-379.

Holmes, R. (1971). The intestinal brush border. Gut, in the press.

Johnson, C. F. (1967). Disaccharidase localization in hamster intestine brush borders. Science, 155, 1670-1672.

Johnson, F. R., and Kugler, J. H. (1953). The distribution of alkaline phosphatase in the mucosal cells of the small intestine of the rat, cat and dog. J. Anat. (Lond.), 87, 247-256.

Miller, D., and Crane, R. K. (1961a). The digestive function of the epithelium of the small intestine. I. An intracellular locus of disaccharide and sugar phosphate ester hydrolysis. Biochim. biophys. Acta (Amst.), 52, 281-293.

Miller, D., and Crane, R. K. (1961b). The digestive function of the epithelium of the small intestine. II. Localization of disac- charide hydrolysis in the isolated brush border portion of intestinal epithelial cells. Biochim. biophys. Acta (Amst.), 52, 293-298.

Nachlas, M. M., Monis, B., Rosenblatt, D., and Seligman, A. M. (1960). Improvement in the histochemical localization of leucine aminopeptidase with a new substrate, L-leucine-4methoxy-2-naphthylamide. J. biophys. bioihem. Cytol., 1, 261-264.

Newey, H., Sanford, P. A., and Smyth, D. H. (1963). Location of function in the Intestinal epithelial cell in relation to carbohydrate absorption. J. Physiol. (Lond.), 168, 423-434.

Oda, T., and Seki, S. (1965). Molecular structure and biochemical function of the microvilli membrane of intestinal epithelial cells, with special emphasis on the elementary particles. $J$. Electron Mic., 14, 210-217.

Olsen, W. A., and Ingelfinger, F. J. (1968). The role of sodium in intestinal glucose absorption in man. J. clin. Invest., 47, 11331142.

Plimmer, R. H. A. (1907). On the presence of lactase in the intestines of animals and on the adaptation of the intestine to lactose. J. Physiol. (Lond.), 35, 20-31.

Roberts, P. J. P., and Whelan, W. J. (1960). The mechanism of carbohydrase action. 5. Action of human salivary $\alpha$-amylase on amylopectin and glycogen. Biochem. J., 76, 246-253.

Schedl, H. P., and Clifton, J. A. (1963). Solute and water absorption by the human small intestine. Nature (Lond.), 199, 1264-1267.

Semenza, G. (1970). Sucrase and sugar transport in the intestine: a carrier-like sugar binding site in the isolated sucrase-isomaltase complex. FEBS Symposium, Vol. 20, pp. 117-130. Academic Press, London and New York. 